\title{
A Rural Population Based Case-Control Study of Senile Cataract in India
}

\author{
Vishnubhatla Sreenivas ${ }^{1}$, Amble K Prabhakar ${ }^{1}$, Sengamedu S Badrinath ${ }^{2}$, Tony Fernandez ${ }^{3}$, \\ Indra S Roy ${ }^{4}$, Tarun Sharma ${ }^{2}$, and Bela Shah ${ }^{1}$
}

\begin{abstract}
Purpose: Senile cataract contributes to $75 \%$ of blindness in India and there is a growing backlog of cataract cases needing surgery. The present study seeks clues to the etiology of senile cataract, so that strategies to prevent or even delay cataract formation could be planned.

Methods: Using a community based case-control design, 258 cases \& 308 controls from one centre and 301 cases \& 591 controls from another were studied. The subjects were from rural areas and were aged 40-60 years. Logistic regression analysis technique was employed to study the associations between senile cataract and various variables.

Results: Systolic blood pressure, duration of exposure to sunlight per day were associated with senile cataract in both the centres $(O R=1.4 \& 1.5$ for systolic $B P$ and $1.6 \& 1.4$ for exposure to sunlight). Utilization of rice gruel $(\mathrm{OR}=0.5)$, duration of exposure to fire \& dust per day $(\mathrm{OR}=1.8)$, family history of cataract (OR=5.0), use of cheap cooking fuels $(O R=1.8)$, increased height $(O R=$ $0.7)$ and increased number of hours of work per day $(O R=0.7)$ were other variables that showed significant association in either of the centres.

Conclusions: Senile cataract appears to have a multi factorial etiology. Though the study provided some clues to the etiology of senile cataract, further studies are needed to know the specific role of these factors in the causation of cataract, so that any preventive or control measures could be initiated in the community. Till such time, we have to fall back on the available surgical approach in control of senile cataract. J Epidemiol, $1999 ; 9$ : 327-336
\end{abstract}

cataract, epidemiology, rural population, regression analysis

Senile cataract is the leading cause of preventable blindness world wide, with an estimated number of 12 to 15 million persons affected ${ }^{1)}$. In India, the prevalence of cataract varies from $30 \%$ to $72 \%$ among the population aged 40 years and above in different parts of the country ${ }^{2)}$ and it was estimated that $75 \%$ of all blind eyes were due to affected lens ${ }^{3}$.

It has been reported that senile cataract develops at an younger age in India as compared to in the developed countries ${ }^{4}$. If the development of cataract could be delayed for 10 years, the number of cases needing surgery would decrease by $45 \%{ }^{11}$.

Though about 1.5 million cataract operations are performed every year in India, there is a growing backlog of cataract cases needing surgery ${ }^{5}$. The present number of cataract surgeries need to be enhanced considerably to cope up with the incident cases of operable cataracts every year. While it is difficult to achieve this in the near future, the costs involved in such a surgical approach will be prohibitive. Under these circumstances, strategies to prevent or even delay cataract formation assume significance. Knowledge on the risk factors of the disease is essential to formulate any such strategy or program. Though earlier studies have pointed out a number of factors having a possible role in cataractogenisis, none has been found to be the specific cause for cataract. The present study is planned as a

Received December 9, 1998 ; accepted April 12, 1999.

'Division of Noncommunicable Diseases, Indian Council of Medical Research, Ansari Nagar, New Delhi, 110 029, India.

"Sankara Nethralaya Chennai, 600006 , India.

${ }^{3}$ Little Flower Eye Hospital, Angamally, Kerala, 683572 , India.

Regional Institute of Ophthalmology, Calcutta, 700 073, India.

Address for correspondence : Dr. V. Sreenivas, Senior Research Officer, Division of Noncommunicable Diseases, Indian Council of Medical Research, Ansari Nagar, New Delhi, 110 029, INDIA. 
case-control study on a rural population to identify the risk factors associated with cataract.

\section{SUBJECTS AND METHODS}

The study was conducted on a rural population during the period from 1986 to 1989 . Villages were selected randomly in each centre and all the population aged between 40 and 60 years in the selected villages were studied. If the target number of cases and controls was not achieved from one village, another village was studied completely and so on. No selected village was studied partly. The centres were identified based on the results of an earlier study on the prevalence of cataract ${ }^{2}$. The centres were Angamally (latitude $9^{\circ} 58^{\prime} \mathrm{N}$, longitude $76^{\circ} \quad 14^{\mathrm{E}} \mathrm{E}$ ) in the state of Kerala, lying in the southwestern parts of the country and Calcutta (latitude $22^{\circ} 32 \mathrm{~N}$, longitude $88^{\circ} 20^{\prime} \mathrm{E}$ ) in the state of West Bengal in the eastern parts of the country. The centre in Angamally i.e The Little Flower Eye Hospital is a 300 bedded, large ophthalmic hospital, having a good mobile unit working in the surrounding rural areas. This ophthalmic hospital is a unit of a 900 bedded general hospital managed by a Missionary. The centre Calcutta refers to the Ophthalmology department of the Medical College, Calcutta. This department was upgraded as a Regional Institute of Ophthalmology by the Government of India with some extended inputs. Likewise in Angamally centre, this Institute too has a sound mobile unit working in the nearby rural areas. Both the centres Angamally and Calcutta belonged to the strata of high or medium prevalence of cataract with a prevalence of $72.2 \%$ and $48.7 \%$ respectively, in the $40+$ years age group ${ }^{2}$.

The criteria for inclusion of cases were 1) persons aged between 40 and 60 years; 2) presence of a lenticular opacity accounting for visual loss as detected by distant direct ophthalmoscopy and 3) visual acuity of 6/9 or less in the involved eye or surgical aphakia. The exclusion criteria were 1) Traumatic, secondary, congenital or complicated cataracts; 2) any other ocular diseases like comeal opacity, uveitis, glaucoma or macular degeneration etc. that can cause diminution of vision independently; 3 ) usage of topical or systemic steroids for a continuous period of 6 weeks or more in the past 2 years; 4) blood pressure more than $160 / 96 \mathrm{~mm} / \mathrm{Hg}$ and 5) random blood sugar more than $160 \mathrm{mg} / \mathrm{dl}$. Persons with best corrected visual acuity of $6 / 9$ or more and with similar exclusion criteria formed the control group.

In the absence of the information on the prevalence of known risk factors and their association with cataract in the Indian population, a sample size of 300 cases with an equal number of controls was decided for each centre. This sample size is expected to provide a power of $80 \%$ to detect an odds ratio of 1.7 or more for a factor whose prevalence in the controls is $15 \%$ in a two sided test at $5 \%$ level of significance.

Study subjects were asked to respond to a standardized ques- tionnaire, which was administered by trained medical social workers. Ophthalmic examination was carried out by ophthalmologists.

The information collected on the subjects include sociodemographic details like religion, educational achievement, marital status, monthly family income, consanguinity of parents etc.; occupational \& environmental aspects like the exposure to sunlight, exposure to fire/dust, protection from sunlight, hours of work per day, years of work, type of cooking fuel used in the household; clinical and physiological variables like previous eye exam, use of glasses, systolic BP, diastolic BP, random blood sugar, pulse rate \& constipation; behavioral variables like smoking, alcohol, tobacco chewing \& nasal snuff habits; other aspects like family history of senile cataract, usage of aspirin. Nutritional aspects like height, weight, usage of vitamin supplements, diet, usage of rice gruel were also collected.

All the subjects had their best corrected visual acuity assessed. Lens examination was carried out with uniocular loupe as well as with a self illuminated ophthalmoscope at 25 $\mathrm{cm}$ using the technique of distant direct ophthalmoscopy. On oblique illumination, a lens showing greyness or spokes of grey opacity (irrespective of cortical, nuclear or mixed predominance) with or without the presence of iris shadow was classified as 'immature cataract'. The lens was termed as 'mature cataract' when no iris shadow was seen and no red reflex was visualized. It was classified as 'hypermature cataract' when in addition, the capsule showed signs of calcification, wrinkling and lens was shrunken in size. For analysis purposes, all cataracts were taken as 'cases'. Intra ocular pressure was measured using the Schiotz tonometer and fundus examination was done after dilating the pupil. Random blood sugar was estimated using the 'Reflocheck' instrument.

Before starting the field work, 2 workshops were held for the participating ophthalmologists, wherein the examination procedures and the classification of subjects were standardized.

The data was collected on standardized proformae. Concurrent reliability and quality control checks were carried out by the investigators through out the study. Ophthalmic Coordinators of the study (SSB \& TS) made concurrent evaluation by making field visits to check the methodology followed, records maintained etc. Study subjects were aiso cross checked on a sample basis for the ophthalmic examination. In addition, the quality of the data was checked by building computerised internal consistency checks before the analysis.

Preliminary analysis of the data included the frequency tabulations of different characteristics, means and standard deviations of the continuous variables and their differences between cases and controls. Risk factor analysis was carried out in two stages. In the first, all study variables were assessed for their association with senile cataract, using a logistic regression analysis, adjusting for age and sex differences between cases 
and controls. In the second stage, all variables that showed at least moderate significance $(p<0.20)$ in the first stage were the candidates for a multivariate model and were analyzed in a step wise manner to arrive at the independent factors that had association with senile cataract. Age and sex were retained as confounders in second stage also. All the analyses were carried out using BMDP DYNAMIC Ver $7.0^{6}$.

\section{RESULTS}

\section{Coverage}

In Angamally centre, 2 villages having 497 households were covered. A total of 2979 persons were enumerated of which 743 (25\%) belonged to the eligible age group i.e between 40 and 60 years. Of the 743 in the eligible age group, 177 persons were excluded due to various reasons, leaving 566 persons ( 258 cases $\& 308$ controls) for the study.

Calcutta centre enumerated 3697 persons in 573 households from 6 villages. Persons in the eligible age group were 1149 (31\%), of which 257 had to be excluded for various reasons. Thus, 892 persons ( 301 cataract cases and 591 controls) were finally included in the study from this centre.

\section{Description of the study subjects}

The age-sex distribution of study subjects in both the centres is shown in Table 1. Females outnumbered males in both cases and controls in the 2 centres. Controls were younger on the average by about 6 years in Angamally and 10 years in Calcutta.

Most of the subjects (99\%) belonged to Hindu religion in Calcutta while in Angamally only $56 \%$ belonged to Hindu religion. Significantly more number of cataract cases were illiterates (both centres); taller (both centres); weighed less (both centres); had previous eye examination (Angamally centre); higher systolic \& diastolic blood pressure (both centres); frequent constipation (Angamally centre); family history of cataract (Angamally centre). Majority of the subjects had a monthly family income of less than Rs. 350 (US\$ 10). Rice gruel or cooked water (remaining water after boiling rice - locally called as kanji) is observed to be utilized in making other food preparations by more number of controls than cases in Angamally.

An excess number of cases reported to have exposure to sunlight (Angamally centre); more number of hours of exposure to sunlight per day (Angamally centre); exposure to fire and/or dust (Angamally centre); more number of hours of exposure to fire/dust per day (Angamally centre). Cases had been working for more number of years (both centres) but controls worked for more number of hours per day (both centres).

Similar proportion of cases and controls were smokers (both centres); majority of the smokers smoked beedies - a local variety, tobacco powder wrapped in a dried Tendu (Diospyros Melanoxylon) leaf. Cases had been smoking for longer duration (Calcutta centre). Significantly higher number of cases reported the tobacco chewing habit (both centres).

No significant differences could be observed in the proportion of persons with alcohol habit or type of alcohol consumed among cases and controls, in either centre. Cataract cases showed an increase of about 2 years in the mean duration of alcohol usage (Calcutta centre) and more number of cases than controls reported daily consumption of alcohol in both the centres.

No significant differences could be observed with respect to the usage of aspirin between cases \& controls - $3.5 \%$ in cases vs $1.6 \%$ in controls and $12.6 \%$ in cases vs $15.4 \%$ in controls in Angamally and Calcutta respectively (Details of data description not shown).

\section{Age-sex adjusted associations of various factors}

As mentioned earlier, there are differences with respect to age and sex between cases and controls and; many of the variables studied are associated with age and sex. Accordingly, estimates of the associations of all study variables with senile cataract are obtained adjusting for the age-sex differences between the cataract cases and controls. These estimates of Odds Ratios obtained by the logistic regression together with 95\% confidence intervals are presented in Table 2.

Table 1. Age-sex distribution of study subjects.

\begin{tabular}{|c|c|c|c|c|c|c|c|c|}
\hline \multirow[t]{3}{*}{ AGE GROUP } & \multicolumn{4}{|c|}{ ANGAMALLY } & \multicolumn{4}{|c|}{ CALCUTTA } \\
\hline & \multicolumn{2}{|c|}{ CASES } & \multicolumn{2}{|c|}{ CONTROLS } & \multicolumn{2}{|c|}{ CASES } & \multicolumn{2}{|c|}{ CONTROLS } \\
\hline & Male & Female & Male & Female & Male & Female & Male & Female \\
\hline $40-44$ & 6 & 12 & 53 & 56 & 5 & 5 & 110 & 168 \\
\hline $45-49$ & 10 & 22 & 37 & 62 & 16 & 8 & 89 & 65 \\
\hline $50-54$ & 32 & 39 & 31 & 26 & 20 & 23 & 27 & 53 \\
\hline $55-60$ & 48 & 89 & 24 & 19 & 96 & 128 & 39 & 40 \\
\hline TOTAL & 96 & 162 & 145 & 163 & 137 & 164 & 265 & 326 \\
\hline Mean & 53.3 & 53.4 & 47.1 & 46.6 & 55.6 & 56.6 & 46.0 & 45.1 \\
\hline Sd & 5.14 & 5.45 & 5.86 & 5.29 & 5.52 & 5.18 & 5.58 & 5.80 \\
\hline
\end{tabular}


Table 2. Age-sex adjusted odds ratios of senile cataract according to different characteristics.

\begin{tabular}{|c|c|c|c|c|c|c|}
\hline \multirow{2}{*}{ VARIABLE } & \multicolumn{3}{|c|}{ ANGAMALLY } & \multicolumn{3}{|c|}{ CALCUTTA } \\
\hline & OR & $\mathrm{p}$ & $95 \%$ C.I & OR & $\mathrm{p}$ & $95 \%$ C.I \\
\hline \multicolumn{7}{|c|}{ SOCIO-DEMOGRAPHIC VARIABLES } \\
\hline $\begin{array}{l}\text { Religion } \\
\text { (Other vs Hindu) }\end{array}$ & 0.96 & 0.81 & $0.64-1.42$ & 0.99 & 0.94 & $0.18-5.34$ \\
\hline $\begin{array}{l}\text { Education } \\
\text { (Illiterate vs Literate) }\end{array}$ & 1.34 & 0.25 & $0.81-2.21$ & 1.20 & 0.46 & $0.75-1.90$ \\
\hline Monthly per capita income & & & & & & \\
\hline$<$ Rs. 300 & 1.00 & - & - & 1.00 & - & - \\
\hline Rs. $300-750$ & 0.96 & 0.84 & $0.59-1.55$ & 0.76 & 0.37 & $0.41-1.38$ \\
\hline$>$ Rs. 750 & 0.81 & 0.59 & $0.37-1.75$ & 0.73 & 0.46 & $0.32-1.66$ \\
\hline Parents relation before marriage & 2.02 & 0.65 & $0.11-39.1$ & 1.00 & 1.00 & - \\
\hline \multicolumn{7}{|c|}{ CLINICAL \& PHYSIOLOGICAL VARIABLES } \\
\hline Previous Eye examination & 1.16 & 0.48 & $0.78-1.72$ & 0.91 & 0.64 & $0.60-1.37$ \\
\hline Usage of glasses & 0.94 & 0.78 & $0.60-1.47$ & 0.67 & 0.07 & $0.43-1.04$ \\
\hline $\begin{array}{l}\text { Systolic BP }(\mathrm{mm} / \mathrm{Hg}) \\
\text { (1 mm increase) }\end{array}$ & $1.03 *$ & $<10^{-4}$ & $1.02-1.05$ & $1.03 *$ & $<10^{-4}$ & $1.02-1.05$ \\
\hline $\begin{array}{l}\text { Diastolic BP }(\mathrm{mm} / \mathrm{Hg}) \\
\text { (1 mm increase) }\end{array}$ & $1.04^{*}$ & 0.01 & $1.01-1.07$ & 1.02 & 0.08 & $1.00-1.04$ \\
\hline $\begin{array}{l}\text { Random blood sugar (mg/dl) } \\
\text { (1 mg increase) }\end{array}$ & 1.01 & 0.13 & $0.99-1.02$ & 1.00 & 0.48 & $0.99-1.01$ \\
\hline Pulse rate & 1.01 & 0.19 & $0.99-1.03$ & 0.96 & 0.08 & $0.92-1.00$ \\
\hline $\begin{array}{l}\text { Constipation } \\
\text { NUTRITIONAL VARIABLES }\end{array}$ & $2.65^{*}$ & 0.01 & $1.33-5.26$ & 0.97 & 0.86 & $0.65-1.46$ \\
\hline $\begin{array}{l}\text { Height }(\mathrm{cm}) \\
(1 \mathrm{~cm} \text { increase })\end{array}$ & 0.98 & 0.13 & $0.94-1.01$ & $0.98^{*}$ & 0.03 & $0.95-1.00$ \\
\hline $\begin{array}{l}\text { Weight }(\mathrm{Kg}) \\
\text { (1 Kg increase) }\end{array}$ & 0.98 & 0.24 & $0.96-1.01$ & 0.99 & 0.61 & $0.97-1.02$ \\
\hline $\begin{array}{l}\text { Diet } \\
\text { (Non-veg } v s \text { Veg.) }\end{array}$ & 0.73 & 0.36 & $0.38-1.42$ & 0.85 & 0.71 & $0.36-1.99$ \\
\hline Vitamin supplements & 0.56 & 0.19 & $0.23-1.35$ & $0.37^{*}$ & 0.03 & $0.15-0.93$ \\
\hline Utilization of rice gruel & $0.40 *$ & 0.005 & $0.21-0.75$ & 0.56 & 0.63 & $0.05-5.95$ \\
\hline $\begin{array}{l}\text { Number of meals per day } \\
(>2 v s<=2)\end{array}$ & 0.79 & 0.23 & $0.53-1.16$ & 4.47 & 0.20 & $0.45-44.4$ \\
\hline
\end{tabular}


Table 2. (Continued)

\begin{tabular}{|c|c|c|c|c|c|c|}
\hline \multirow{2}{*}{ VARIABLE } & \multicolumn{3}{|c|}{ ANGAMALLY } & \multicolumn{3}{|c|}{ CALCUTTA } \\
\hline & OR & $\mathrm{p}$ & 95\% C.I & OR & $\mathrm{p}$ & 95\% C.I \\
\hline \multicolumn{7}{|c|}{ OCCUPATIONAL \& ENVIRONMENTAL VARIABLES } \\
\hline Exposure to sunlight & $1.64^{*}$ & 0.02 & $1.08-2.48$ & 1.28 & 0.32 & $0.79-2.07$ \\
\hline $\begin{array}{l}\text { Hours of sunlight exp./day } \\
\text { ( } 1 \text { hour increase) }\end{array}$ & $1.16^{*}$ & 0.01 & $1.03-1.30$ & 1.06 & 0.19 & $0.97-1.17$ \\
\hline Exposure to fire/dust & $2.09 *$ & 0.002 & $1.33-3.30$ & 1.59 & 0.06 & $0.97-2.61$ \\
\hline $\begin{array}{l}\text { Hours of exp. to fire/dust } \\
\text { ( } 1 \text { hour increase) }\end{array}$ & $1.27 *$ & $<10^{-4}$ & $1.12-1.44$ & 1.06 & 0.22 & $0.97-1.15$ \\
\hline Protection from sunlight & 1.11 & 0.86 & $0.26-4.83$ & 1.00 & 1.00 & - \\
\hline $\begin{array}{l}\text { Hours of work/day } \\
\text { (1 hour incrase) }\end{array}$ & $1.12^{*}$ & 0.02 & $1.01-1.24$ & $0.91^{*}$ & 0.01 & $0.84-0.98$ \\
\hline $\begin{array}{l}\text { How long working (years) } \\
\text { (1 year increase) }\end{array}$ & 1.00 & 0.76 & $0.98-1.03$ & 0.98 & 0.06 & $0.96-1.00$ \\
\hline $\begin{array}{l}\text { Cooking fuel used } \\
\text { (Wood/Cow dung vs Other) }\end{array}$ & 0.37 & 0.51 & $0.02-6.65$ & $2.06^{*}$ & $<10^{-3}$ & $1.31-3.23$ \\
\hline \multicolumn{7}{|l|}{ BEHAVIORAL VARIABLES } \\
\hline Smoking & 1.53 & 0.27 & $0.71-3.27$ & 1.15 & 0.65 & $0.63-2.11$ \\
\hline $\begin{array}{l}\text { Duration of smoking (years) } \\
\text { (1 year increase) }\end{array}$ & 1.02 & 0.19 & $0.99-1.06$ & 1.01 & 0.23 & $0.99-1.03$ \\
\hline $\begin{array}{l}\text { Number smoked/day } \\
\text { (1 piece increase) }\end{array}$ & $1.04 *$ & 0.03 & $1.00-1.08$ & 1.01 & 0.47 & $0.98-1.04$ \\
\hline Chewing habit & 1.41 & 0.10 & $0.93-2.14$ & 1.42 & 0.15 & $0.88-2.31$ \\
\hline $\begin{array}{l}\text { Money spent on chewing/day } \\
\text { (1 paise increase) }\end{array}$ & $1.01^{*}$ & 0.05 & $1.00-1.03$ & 1.01 & 0.44 & $0.98-1.04$ \\
\hline Nasal snuff habit & 1.40 & 0.53 & $0.49-4.02$ & 1.00 & 0.99 & $0.46-2.16$ \\
\hline $\begin{array}{l}\text { Money spent on snuff/day } \\
\text { (1 paise increase) }\end{array}$ & 1.02 & 0.49 & $0.96-1.08$ & 1.01 & 0.77 & $0.96-1.05$ \\
\hline $\begin{array}{l}\text { Alcohol consumption } \\
\text { Type of alcohol consumed }\end{array}$ & 1.57 & 0.14 & $0.85-2.88$ & 1.59 & 0.11 & $0.89-2.84$ \\
\hline None & 1.00 & - & - & 1.00 & - & - \\
\hline Indian Made Foreign Liquor & 2.99 & 0.06 & $0.93-9.69$ & 1.54 & 0.14 & $0.86-2.77$ \\
\hline Local varieties & 1.43 & 0.26 & $0.77-2.68$ & 2.90 & 0.30 & $0.38-22.0$ \\
\hline \multicolumn{7}{|c|}{ Frequency of alcohol consumption } \\
\hline Nil & 1.00 & - & - & 1.00 & - & - \\
\hline Less than daily & 0.71 & 0.36 & $0.34-1.48$ & 0.71 & 0.48 & $0.28-1.82$ \\
\hline Daily & $4.84 *$ & 0.001 & $1.99-11.8$ & $2.10^{*}$ & 0.03 & $1.07-4.12$ \\
\hline $\begin{array}{l}\text { Years of alcohol consumption } \\
\text { (1 year increase) }\end{array}$ & 1.02 & 0.28 & $0.98-1.06$ & $1.03 *$ & 0.02 & $1.00-1.06$ \\
\hline \multicolumn{7}{|l|}{ OTHER VARIABLES } \\
\hline Usage of aspirin & 1.76 & 0.36 & $0.53-5.90$ & $0.58 *$ & 0.04 & $0.34-0.98$ \\
\hline Family history of cataract & $5.22 *$ & $<10^{-4}$ & $3.17-8.59$ & 1.16 & 0.49 & $0.76-1.78$ \\
\hline
\end{tabular}

The variables that have shown significant $(\mathrm{p}<0.05)$ association with senile cataract in both centres are systolic BP (OR = 1.03 in both centres), 1 hour increase of work per day (OR = 1.12 in Angamally \& 0.91 in Calcutta) and daily consumption of alcohol ( $\mathrm{OR}=4.84$ in Angamally \& 2.10 in Calcutta).

The variables that showed significant association in only Angamally centre are: diastolic $\mathrm{BP}(\mathrm{OR}=1.04)$, constipation $(\mathrm{OR}=2.65)$, family history of cataract $(\mathrm{OR}=5.22)$, utilization of rice gruel $(\mathrm{OR}=0.40)$, exposure to sunlight $(\mathrm{OR}=1.64)$, one hour increase in the duration of exposure to sunlight per day $(O R=1.16)$, exposure to fire/dust $(O R=2.09)$, one hour increase in the duration of exposure to fire/dust per day (OR = 1.27 ) and the number smoked per day $(O R=1.04$, for one piece increase).

Similarly, the variables that showed significant association with cataract in Calcutta centre only are: one $\mathrm{cm}$ increase in height ( $O R=0.98)$, consumption of vitamin supplements (OR $=0.37$ ), one year increase in the duration of alcohol consump- 
tion ( $\mathrm{OR}=1.03)$, usage of cheap cooking fuels such as wood $\&$ cow dung $(O R=2.06)$ and usage of aspirin $(O R=0.58)$.

In addition to these, some more variables showed a moderate association with senile cataract $(0.05<\mathrm{p}<0.20)$. They are tobacco chewing habit, alcohol consumption habit and type of alcohol consumed in both Angamally \& Calcutta; $1 \mathrm{mg}$ increase in the random blood sugar level, pulse rate, $1 \mathrm{~cm}$ increase in height, consumption of vitamin supplements, one year increase in the duration of smoking and money spent on chewing per day in Angamally centre and; usage of prescription glasses, $1 \mathrm{~mm}$ increase in diastolic BP, more than 2 meals a day, one hour increase in the duration of exposure to sunlight per day, exposure to fire/dust and one year increase in the duration of work in Calcutta centre.

\section{Multivariate analysis}

As indicated above, 21 variables in Angamally and 17 variables in Calcutta showed significant or moderately significant association with senile cataract after adjusting for age-sex differences between cases and controls. All such variables with at least a moderately significant association were put into a multiple logistic regression analysis in a step-wise manner, separately for the 2 centres, to arrive at the independent set of variables that have significant association with senile cataract.

In the multivariate analysis, some of the variables were considered in a slightly different way from the preliminary analysis. Systolic and diastolic BP were considered as continuous variables in units of $10 \mathrm{~mm} / \mathrm{Hg}$. Hours of work per day, hours of exposure to sunlight and fire/dust per day were considered as continuous variables in units of 2 hours. Height was considered in units of 15 centimeters and pulse rate was considered in units of 10 . This is done to reduce the number of different covariate strata, so that more concise estimates of the associations could be obtained.

Age and sex were entered as confounders at step number zero and were retained till the last step, irrespective of their significance. The results of multiple logistic regression analysis are shown in Table 3.

It can be seen that 2 hour increase in the exposure to sunlight per day and $10 \mathrm{~mm}$ increase in the systolic BP are significantly positively associated with senile cataract in both Angamally and Calcutta centres (ORs $1.63 \& 1.41$ for exposure to sunlight and $1.45 \& 1.49$ for systolic BP in Angamally and Calcutta respectively). Apart from these 2 variables common to both centres, Angamally centre showed 3 more variables, viz. history of senile cataract in the family (OR $=5.01), 2$ hour increase in exposure to fire/dust $(\mathrm{OR}=1.85)$ and utilization of rice gruel $(O R=0.49)$. Similarly Calcutta centre exhibited 3 more variables as significantly associated in addition to the 2 common variables and they are $15 \mathrm{~cm}$ increase in height (OR = $0.67), 2$ hour increase in work per day $(O R=0.66)$ and usage of cheap cooking fuels such as wood \& cow dung etc. (OR =
$1.82)$.

To know how good the logistic model fitted the data, a summary measure - Hosmer Lemeshow goodness of fit chi-square ${ }^{2}$ is computed and the results are shown in the bottom panel of Table 3. We can see that the goodness of fit chi-square with 8 degrees of freedom is 4.04 and 5.56, leading to $p$ values of 0.85 and 0.70 in Angamally and Calcutta respectively. Thus the model fitted the data reasonably well. Another way of knowing the goodness of the fitted model is to compute the proportion of subjects that could be predicted or classified correctly. Receiver Operating Characteristic (ROC) curve analysis ${ }^{8)}$ indicated that the final set of variables obtained by the multiple logistic model could classify $87.0 \%$ of subjects in Angamally and $91.2 \%$ in Calcutta correctly. This analysis too indicated that the fitted model is good.

The details of step-wise analysis - the variable that entered, the $\log$ likelihood, improvement chi-square with it's $p$ value and the goodness of fit chi-square with it's $p$ value at each step in the two models for the two centres are shown in Table 4.

\section{DISCUSSION}

The potential sources of bias need to be considered before interpreting any epidemiological findings.

Since our study is population based, the scope for selection bias as such is limited in contrast to a hospital based one. All the eligible subjects were studied in the selected villages, leaving a few who refused to co-operate. This non-cooperative group was $7 \%$ in Angamally \& $12 \%$ in Calcutta and hence the selection bias does not play any significant role.

The information on different study variables was collected by the medical social workers who were masked as to the status of each subject (case or control) as far as possible. Thus, the scope for any interviewer bias in the data collection is reduced.

To minimize the misclassification - another potential source of bias, visual acuity criteria is incorporated in the definition of 'case' and 'control'. Subjects with vision loss due to conditions other than cataract were excluded. So cases were most probably true cases. Controls were required to have normal vision to increase the probability of a control being a true control. In addition, as mentioned earlier, 2 workshops were conducted for the participating investigators in which a consensus on the diagnosis and other clinical procedures was achieved. However, it is possible that some of the subjects may have nascent lenticular opacities that might not yet affect the visual acuity and such subjects could have been diagnosed as 'controls'. To that extent, the results of this study could be underestimates of the true magnitudes of association.

The literature review on risk factor identification of senile cataract indicated that most of the studies were descriptive in nature and a few number of studies used a classical case-con- 
Table 3. Factors* associated with senile cataract based on multiple logistic regression analysis.

\begin{tabular}{|c|c|c|c|c|}
\hline \multirow{2}{*}{ VARIABLE } & \multicolumn{2}{|c|}{ ANGAMALLY } & \multicolumn{2}{|c|}{ CALCUTTA } \\
\hline & OR & $95 \%$ C.I & OR & 95\% C.I \\
\hline History of cataract in the family & 5.01 & $2.93-8.56$ & - & - \\
\hline Hours of exposure to fire \& dust & 1.85 & $1.43-2.40$ & - & - \\
\hline Utilization of rice gruel & 0.49 & $0.24-1.00$ & - & - \\
\hline Hours of exposure to sunlight/day & 1.63 & $1.27-2.10$ & 1.41 & $1.12-1.77$ \\
\hline Systolic Blood Pressure (mm/Hg) & 1.45 & $1.21-1.73$ & 1.49 & $1.27-1.75$ \\
\hline Height (Cms) & - & - & 0.67 & $0.48-0.94$ \\
\hline Hours of work/day & $\longrightarrow$ & - & 0.66 & $0.52-0.83$ \\
\hline Wood/cow dung as cooking fuel & - & - & 1.82 & $1.13-2.92$ \\
\hline $\begin{array}{l}\text { Goodness of Chi-Square } \\
\text { (Hosmer-Lemeshow) }\end{array}$ & & & & \\
\hline Degrees of freedom & & 8 & & 8 \\
\hline pvalue & & 85 & & \\
\hline$\%$ correct classification $^{\Theta}$ & & .0 & & \\
\hline
\end{tabular}

Table 4. Summary of stepwise results of logistic regression analysis.

\begin{tabular}{|c|c|c|c|c|c|c|}
\hline \multirow{2}{*}{$\begin{array}{l}\text { STEP } \\
\text { NO. }\end{array}$} & \multirow[t]{2}{*}{ DF } & \multirow{2}{*}{$\begin{array}{c}\text { LOG } \\
\text { LIKELIHOOD }\end{array}$} & \multicolumn{2}{|c|}{ IMPROVEMENT } & \multicolumn{2}{|c|}{ GOODNESS OF FIT } \\
\hline & & & CHI-SQ. & P-VAL & CHI-SQ. & P-VAL \\
\hline \multicolumn{7}{|c|}{ ANGAMALLY CENTRE } \\
\hline 0. & & -305.826 & & & 611.653 & 0.072 \\
\hline 1. Family history & 1 & -282.124 & 47.403 & 0.000 & 564.248 & 0.454 \\
\hline $\begin{array}{l}\text { 2. Hours of exposure } \\
\text { to fire \& dust }\end{array}$ & 1 & -273.056 & 18.136 & 0.000 & 546.113 & 0.655 \\
\hline $\begin{array}{l}\text { 3. Hours of exposure } \\
\text { to sunlight }\end{array}$ & 1 & -266.510 & 13.093 & 0.000 & 533.019 & 0.779 \\
\hline 4. Systolic BP & 1 & -258.194 & 16.630 & 0.000 & 516.389 & 0.896 \\
\hline $\begin{array}{l}\text { 5. Utilization of } \\
\text { rice gruel }\end{array}$ & 1 & -256.239 & 3.911 & 0.048 & 512.479 & 0.912 \\
\hline \multicolumn{7}{|l|}{ GALCUTTA CENTRE } \\
\hline 0. & & -342.202 & & & 661.178 & 1.000 \\
\hline 1. Systolic BP & 1 & -328.706 & 26.992 & 0.000 & 634.183 & 1.000 \\
\hline 2. Cooking fuel & 1 & -323.830 & 9.750 & 0.002 & 624.433 & 1.000 \\
\hline $\begin{array}{l}\text { 3. Hours of work } \\
\text { per day }\end{array}$ & 1 & -320.201 & 7.259 & 0.007 & 617.175 & 1.000 \\
\hline $\begin{array}{l}\text { 4. Hours of exposure } \\
\text { to sunlight }\end{array}$ & 1 & -316.068 & 8.265 & 0.004 & 608.909 & 1.000 \\
\hline 5. Height & 1 & -313.290 & 5.556 & 0.018 & 603.353 & 1.000 \\
\hline
\end{tabular}

trol design. The present case-control study has identified some factors having positive association and some having negative association with senile cataract.
Systolic blood pressure is found to be significantly positively associated in both the centres. This observation supports the earlier studies both from India ${ }^{9,10)}$ and also from 
other places ${ }^{11-14)}$. This finding is to be noted in the light that persons with systolic BP of more than $160 \mathrm{~mm} / \mathrm{Hg}$ are excluded in the study and the observed magnitude of association is for the limits of systolic BP included in the study. Further, the details of duration of raised systolic BP (within the limits of inclusion criteria) and any medications being used by the subjects etc. need to be considered to understand the role of systolic BP in the causation of cataract.

We found the exposure of sunlight per day is significantly associated with senile cataract. A linear dose-response relation was also observed with the increased duration of exposure per day. The odds ratios of cataract were 1.6, 2.8 and 4.4 for $1-2$ hours, 3-4 hours and more than 4 hours of exposure to sunlight per day respectively. This is in conformity with the widely accepted hypothesis of cataract and ultraviolet rays association. Many studies reported significant association between cataract and sunlight or ultra-violet exposure ${ }^{10,1522)}$. Knowledge on the irradiated dose of solar UV rays to the earth in the study areas would be helpful in understanding or interpreting this result. But such data is not available. Available meteorological data indicate that average number of days of a year when the low cloud cover is nil or less than 2 Oktas was 33\% in Angamally and $64 \%$ in Calcutta areas.

A significant association of cataract with the hours of exposure to fire/dust was observed in Angamally centre. The exposure to dust is mainly due to the occupation where many of the rural people in the state of Kerala are involved in coir industry, using the coconut fibre and studies have shown the toxicity of coir fibre, both In vitro and In vivo ${ }^{\text {2) }}$. As in the case of duration of exposure to sunlight, linear dose response relation was also observed with the increased duration of hours of exposure to fire/dust per day. The odds ratios were $1.8,3.2$ and 7.9 for 1 2 hours, 3-4 hours and more than 4 hours of exposure to fire \& dust per day.

Usage of cheap cooking fuels such as wood and cow dung was associated with senile cataract in Calcutta centre. This is similar to the earlier report from a hospital based case-control study in India ${ }^{10}$. The persons who use such cooking fuels generally have poor economic status and further, traditionally females are more exposed to such cooking fuels than males. Stratified analyses on sex confirmed the existence of significant association between the usage of such fuels and cataract in both the sex groups (ORs 1.8 and 2.2 with $\mathrm{p}$ values 0.02 and 0.002 in males \& females respectively). However, similar analysis on income indicated a significant association in lower income group only, suggesting that the association could be due to poor economic status and associated factors. Whether such cheap fuels produce more eye irritants that cause senile cataract needs to be examined.

The present study identified that increased number of hours of work per day has lesser risk of cataract in Calcutta centre. An alternative explanation for this observation could be that controls being younger, work for more number of hours a day showing this variable as a protective factor. But as already mentioned, the age-sex differences between the cases and controls are adjusted in the multivariate analysis. To examine this association further, separate analysis was carried out in subjects aged 40-49 years and 50-60 years. Both strata showed similar magnitude of association with cataract, OR \& $95 \% \mathrm{CI}$ being $0.63,0.37-1.08$ and $0.66,0.50-0.86$ respectively. A somewhat similar finding was also reported ${ }^{100}$ earlier - hours per week doing 'near' work has lesser risk for all types of cataract.

Thus, these observations of significant association of cataract with sunlight exposure, exposure to fire/dust, hours of work per day and usage of cheap cooking fuels implicate the environment as a potential factor in the causation of senile cataract.

Family history of cataract was significantly associated with cataract in Angamally centre. This finding could be related to the general health awareness or literacy levels in the populations studied, because a literate person is more likely to be aware of cataract in general. Stratified analysis on literacy status confirmed the association of family history with cataract, the odds ratios being $5.4 \& 4.6$ in illiterates and literates respectively. Thus, the association persisted irrespective of the literacy status. This observation reveals a genetic angle to cataractogenisis, which has also been reported earlier $\left.{ }^{19}, 20,24\right)$. Evidence for a major gene for cortical cataract has also been suggested recently ${ }^{25}$. Further studies are needed to confirm as well as to elucidate the mechanisms of action, if any etc. in this regard.

Usage of rice gruel showed significant protection from cataract in Angamally centre. Rice gruel is the excess water in cooking rice. It is a common practice in India, more so in rural areas that rice is cooked in open vessels with excess water, which is subsequently discarded. This excess water, which is drained off after cooking contains vitamins, minerals, amino acids, sugars and gelatinized starch ${ }^{20}$. It can be used for thickening of soups and in puddings or can be consumed as such after flavoring or mixing with buttermilk. It can also be used in the preparation of other food items. Rural people discard such nutrient rich component due to ignorance.

Increased height was observed to be significantly protective against senile cataract in Calcutta centre. Height and usage of rice gruel indicate nutritional status of a person. This observation supports the earlier reports of increased body mass index (weight/height $\left.{ }^{2}\right)^{10)}$ and increased weight ${ }^{9)}$ having significant association with decreased risk of nuclear \& mixed types of cataracts and senile cataract in general, respectively, in two hospital based studies from India. However, an increased risk of cataract with an increase in BMI was observed in a prospective cohort study ${ }^{27}$.

Though nutritional deficiencies have been reported to be causing cataract in many animals, their role in human catarac- 
togenisis is still not very clear. A positive association between cataract and low frequency of protein foods consumption in the Punjab area of northern India was reported ${ }^{4}$. A population based cohort study from Wisconsin indicated that intake of vitamin supplements and certain foods may explain associations of several nutrients with risk for nuclear sclerosis ${ }^{28)}$.

We did not find any association of aspirin usage with cataract. Association between aspirin usage and cataract has been inconclusive with some reports suggesting a protective effect of aspirin or 'aspirin-like' analgesics in the causation of cataract ${ }^{10,2932)}$ while some reporting no relationship between the usage of aspirin and cataract among general population ${ }^{33-35)}$ and among diabetics also ${ }^{36}$.

To summarize, the present study attempted to find clues to the etiology of senile cataract using a population based casecontrol study design and employing multivariate analysis techniques in 2 rural centres of India. Systolic blood pressure, duration of exposure to sunlight per day were associated with senile cataract in both the centres. Utilization of rice gruel, duration of exposure to fire \& dust per day, family history of cataract, use of cheap cooking fuels, increased height and number of hours of work per day were other variables that showed significant association in either centre. The factors identified in the two centres are not same. This could be due to the fact that we have studied cataract cases as a single entity and the distribution of subtypes of cataract viz. cortical, nuclear, posterior subcapsular and mixed types in the two centres may be different ${ }^{37}$. Some studies did suggest different epidemiology for different subtypes of cataract ${ }^{10,19,38}$. Such studies involving detailed slit lamp microscopy on population from remote rural areas with no proper road access and electricity supply are not yet practically feasible in many developing countries, including India.

In conclusion, the development of senile cataract is a complex multi factorial process. Though the findings of this study improve our understanding of cataract development, unfortunately some of the factors identified to have significant association are not amenable for any intervention. Also, further studies are needed to confirm these findings and also to explain the exact mechanisms of action of these factors in the causation of cataract to facilitate initiation of preventive or control measures. Till such time, we may have to rely on the available surgical measures only.

\section{ACKNOWLEDGEMENTS}

This paper emanates from the ICMR's 'Collaborative Study on Cataract, Phase-II'. We thank the Steering Committee members viz. Drs. S.K. Angra, S.P. Dhir, Usha K. Luthra, R. Nath and C.R. Ramachandran and K. Ramachandran for their advice in planning $\&$ conducting this study.

\section{REFERENCES}

1. Kupfer $\mathrm{C}$. The Conquest of cataract: a global challenge. Trans Ophthalmol Soc UK 1984; 104: 1-10.

2. Mohan M. Collaborative Study on Prevalence of Cataract. Indian Council of Medical Research, 1990, New Delhi.

3. Mohan M. Collaborative Study on Blindness (1971-74) A Report. Indian Council of Medical Research, 1987, New Delhi.

4. Chatterjee A, Milton R C and Thyle S. Prevalence and aetiology of Cataract in Punjab. Br J Ophthalmol 1982; 66: 35-42.

5. Directorate General of Health Services. Present Status of National Program For Control of Blindness (NPCB). Government of India, 1992, New Delhi.

6. BMDP Statistical Software Ver. 7.0. University of California. Los Angeles.

7. Hosmer D W and Lemeshow $\mathbf{S}$. A goodness of fit test for the multiple logistic regression model. Commun. Statist 1980; A10: 1043-1069.

8. Hanley J A and McNeil B J. The meaning and use of the area under a receiver operating characteristic (ROC) curve. Radiology 1982; 143: 29-36.

9. Badrinath S S, Tarun Sharma, Jyotirmoy Biswas and Srinivas V. A Case Control Study of Senile Cataract in a Hospital Based Population. Ind J Ophthalmol 1996; 44: 213-217.

10. Mohan M, Sperduto R D, Angra S K et al. India-US Case Control study of age-related cataracts. Arch Ophthalmol 1989; 107: 670-676.

11. Hiller R, Sperduto R D, Ederer F. Epidemiologic associations with nuclear, cortical and posterior subcapsular cataracts. Am J Epidemiol 1986; 124: 916-925.

12. Kahn H A, Leibowitz H M, Ganley J P, Kini M M. The Framingham Eye Study II: Association of ophthalmic pathology with single variables previously measured in Framingham Heart Study. Am J Epidemiol 1977; 106: 33-41.

13. Burgess C A, Sowers M. Systemic hypertension and senile cataracts: an epidemiologic study. Optom Vis Sci 1992; 69: 320-324.

14. Klein B E, Klein R, Jensen S C, Linton K L. Hypertension and lens opacities from the Beaver Dam Eye Study. Am j Ophthalmol 1995; 119: 640-646.

15. Hiller R, Sperduto R D, Ederer F. Epidemiologic associations with cataract in the 1971-1972 National Health and Nutrition Examination Survey. Am J Epidemiol 1983; 118: 239-249.

16. Hiller R, Giacometti L, Yuen K. Sunlight and cataract: An epidemiologic investigation. Am J Epidemiol 1977; 105: 450-459. 
17. Hollows F, Moran D. Cataract - the ultraviolet risk factor. Lancet 1981; ii: 1249-1250.

18. Katoh N, Sasaki K, Shihata T et al. Case-Control study of senile cataract in Japan: a preliminary report. Jpn $\mathbf{j}$ Ophthalmol 1993; 37: 467-477.

19. The Italian-American Cataract Study Group. Risk factors for age-related cortical, nuclear and posterior subcapsular cataracts. Am j Epidemiol 1991; 133: 541-543.

20. Leske M C, Chylack L T Jr, Wu S Y. The Lens Opacities Case-Control Study. Risk factors for Cataract. Arch Ophthalmol 1991; 109: 244-251.

21. Burton M, Fergusson E, Hart A, Knight K, Lary D, Liu C. The prevalence of cataract in two villages of northern Pakistan with different levels of ultraviolet radiation. Eye 1997; 11: 95-101.

22. Hirvela $\mathrm{H}$, Luukinen $\mathrm{H}$, Laatikainen L. Prevalence and risk factors of lens opacities in the elderly in Finland. A population-based study. Ophthalmology 1995; 102: 108117.

23. Saxena R P, Dogra R K, Bhattacherjee J W. Coir fibre toxicity: In vivo and In vitro studies. Toxicol Lett 1982; 10: 359-365.

24. Familial aggregation of lens opacities: the Framingham Eye Study and the Framingham Offspring Eye Study. Am j Epidemiol 1994; 140: 555-564.

25. Heiba I M, Elston R C, Klein B E, Klein R. Evidence for a major gene for cortical cataract. Invest Ophthalmol Vis Sci 1995; 36: 227-235.

26. Council of Scientific \& Industrial Research 1966. The Wealth of India. A Dictionary of Indian Raw Materials and Industrial Products. Vol VII. pp 174.

27. Glynn R J, Christen W G, Manson J E, Bernheimer J, Hennekens $\mathrm{C} \mathrm{H}$. Body mass index. An independent predictor of cataract. Arch Ophthalmol 1995; 113: 1131-
1137.

28. Mares Perlman J A, Brady W E, Klein B E, Klein R, Haus G J, Palta M, Ritter L L, Shoft S M. Diet and nuclear lens opacities. Am j Epidemiol 1995; 141: 322334.

29. Cotlier E, Sharma Y R. Senile cataract: Evidence for acceleration by diabetes and deceleration by salicylate. Can J Ophthalmol 1981; 16: 113-118.

30. Cotlier E. Aspirin and senile cataract in rheumatoid arthritis. Lancet 1981; i: 338-339.

31. Van Heyningen $R$, Harding J J. Do aspirin-like analgesics protect against cataract ?. Lancet 1986; i: 1111-1113.

32. Harding J J, Egerton M, Harding R S. Protection against cataract by aspirin, paracetamol and ibuprofen. Acta Ophthalmol Copenh 1989; 67: 518-524.

33. Peto R, Gray R, Collins R et al. Randomised trial of prophylactic daily aspirin in British male doctors. $\mathrm{Br}$ Med $\mathrm{J}$ 1988; 296: 313-316.

34. Siegel D, Sperduto R D, Ferris F L III. Aspirin and cataracts. Ophthalmol 1982;89:47A-49A.

35. West S K, Munoz B E, Newland H S, Emmet E A, Taylor H R. Lack of evidence for aspirin use and prevention of cataracts. Arch Ophthalmol 1987; 105: 1229 1231.

36. Klein B E, Klein R, Moss $\mathrm{S}$ E. Is aspirin use associated with lower rate of cataracts in diabetic individuals ? Diabetes Care 1987; 10: 495-499.

37. West S K, Valmadrid C T. Epidemiology of risk factors for age-related cataract. Surv Opthalmol 1995; 39: 323 334.

38. Miglior S, Marighi P E, Musicco M, Balestreri C, Nicolosi A, Orzalesi N. Risk factors for cortical, nuclear, posterior subcapsular and mixed cataract: a case-control study. Ophthalmic Epidemiol 1994; 1: 93-105. 